\title{
Geo-locating Ruskin's Mornings in Florence and Jeanneret's Sketches and Watercolours from his 1907 Voyage
}

\author{
J. Kirk Irwin \\ Architect \\ 55 East Monroe \# 3800 \\ Chicago, IL 60603, USA \\ Jkirkirwin@gmail.com
}

\begin{abstract}
This paper shows how the application of geo-location tools facilitates the analysis of Jeanneret/Le Corbusier's experience of medieval art and architecture during his 1907 Voyage to Florence. While Jeanneret/Le Corbusier's 1911 Voyage is better known, his 1907 Voyage provides an opportunity to study the cross-historical influence of medieval art, architecture and urbanism on the development of Early Modernism. Methods of analysis that employ digital technologies allow for new explorations of this body of work. Geo-location tools are particularly applicable as they reveal patterns and themes that would otherwise go unrecognised. Several of these will be discussed as to their suitability in support of this research.
\end{abstract}

Digital humanities. Visualisation. Art history. Perspective.

\section{INTRODUCTION}

Charles-Edouard Jeanneret's 1907 visit to Florence is essential to the question of his interest in medieval art and architecture. What sets Jeanneret's experience apart from other artists at the time with similar interests is that he experienced this environment as a relatively young man as he completed his early training at the Ecole des Arts in La Chaux de Fonds, Switzerland. The curriculum in which he studied included an exposure to the writings of John Ruskin. Jeanneret references Ruskin's Mornings in Florence in a correspondence to his mentor and teacher L'Eplattenier (Brooks 1997). Based on this it is thought that he had a copy of the Ruskin text with him during his visit to Florence (Brooks 1997). The location of many of Jeanneret's sketches produced during his 1907 visit match many of the locations suggested by Ruskin.

That Jeanneret "learned to see" while immersed in the medieval urban schema of Florence is significant. Trachtenberg argues that it was medieval Florence that provided the spatial conditions within which Brunelleschi developed some form of representational perspective (Trachtenberg 1988, 1997). Brunelleschi was known to have produced several studies of the urban condition in Florence including one at the St. John Baptistery and the other at the Piazza della Signoria. Trachtenberg proposes that there are locations within the urban scheme that provide insights into medieval spatiality at an urban scale, and that his informed the development of linear perspective.

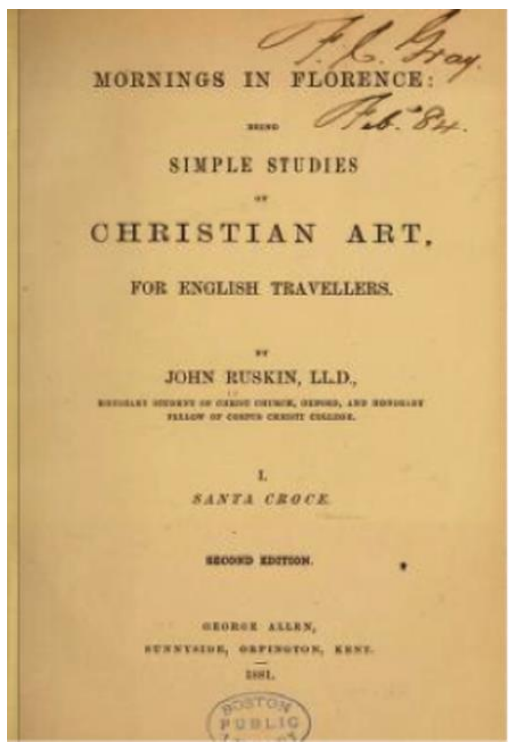

Figure 1: Title Page, Mornings in Florence. 
Do any of these locations overlap those suggested by Ruskin? Do any of these overlap the locations of Jeanneret's sketches and watercolours? How might medieval spatiality have affected Le Corbusier's Modernist expressions of space in his paintings and architecture?

\section{GOALS}

Ruskin's Mornings in Florence (Figure 1) presents a six-day itinerary for travellers around the turn of the twentieth century. He presents a sequence leading from familiar sites, including Santa Croce, the Duomo, and Santa Maria Novella (Ruskin 1891).

Jeanneret's experience of Florence is mediated by Ruskin. This is primarily though his selection of sites and art, with its emphasis on work prior to the Renaissance, and secondly, through the dynamics of movement.

This implies a process of perception that is dynamic; with dynamic perception understood as movement around an object or through a space, movement from one place to another as a process of perception, and movement toward and away from the object or space.

What tools may be developed that help to facilitate a study that places as much emphasis on the dynamic qualities of art and architecture as on the art as an isolated art product?

Essential to achieving this goal is to create a place-based gallery of images with links to pertinent scholarship, images of Jeanneret/Le Corbusier's sketches (Figure 2), and street views. These could be linked to place markers along a specific itinerary. Various itineraries may be compared. The gallery and scholarship links are place-based geo-located within a dynamic database of knowledge. This allows for a new conceptualization of the data.

\section{OPTIONS}

This paper focuses on the digital tools that are available at no cost that might facilitate the development of research around these questions. With several alternatives available what is the most appropriate tool for this task? What criteria should be applied in assessing alternative tools?

There are several criteria. The first is cost. While some alternatives are available at no cost others require a monthly fee for access to their full platform. The third is the capacity of the platform

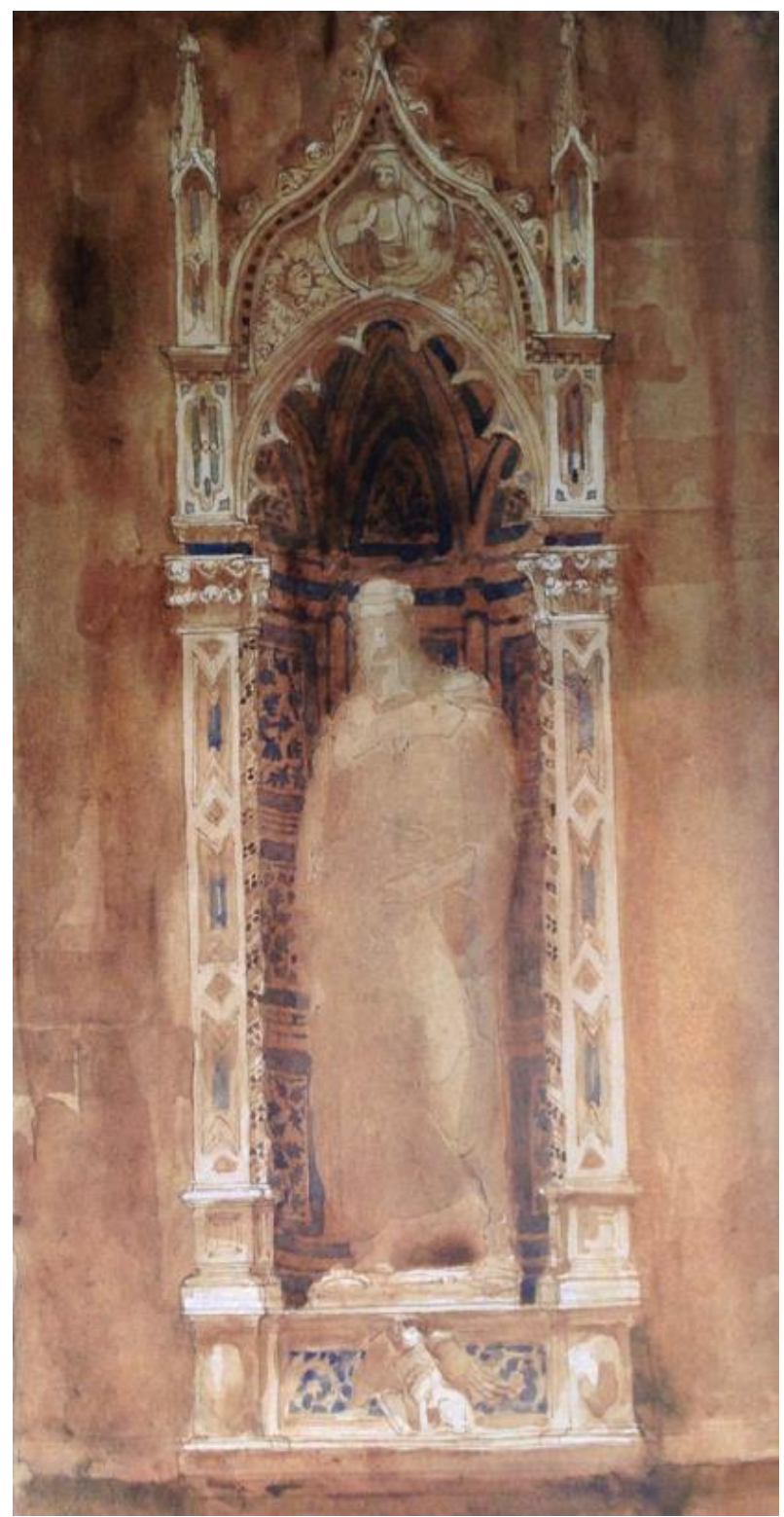

Figure 2: St. Mark, sketch by Jeanneret/Le Corbusier, sculpture by Donatello, FLC 2162 (Brillhart 2016).

to link a variety of information sources to multiple locations.

While there are some programs that address one or the other of these criteria well, the options available to the researcher or historian that allow for the most flexibility and ease of use. The following platforms were compared: Mapbox, Palladio, Wordpress Basic, and Carto.

Beginning with Mapbox, this is a mapping tool that does well with data visualization when the data is statistically based. The criteria for this project present a unique challenge for a platform such as Mapbox in that the goal is to assess the locations and characteristics of material that is already visualised in the form of paintings and sketches. What this project asks of the digital tool is to locate 
the visual material within a geographic framework and allow for comparisons. Mapbox takes raw data and creates a visual image with it. The results are an impressive array of visually compelling images, but this is not the goal of this project.

A second platform is Palladio, named after the Renaissance architect Andrea Palladio. As with Mapbox, the mapping images are well presented, but the platform has limitations. First, is that there is no capacity within Palladio to store one's work. This means that it is necessary to create a visualisation then save the visualization as a static image for further reference. This limitation would limit its use for projects that have an extended time frame or projects with multiple users. Locations plotted on Palladio's maps are not interactive and are therefore not linkable to external sources of information.

Wordpress Basic also provides a mapping tool. Wordpress provides information windows linked to specific locations. But the Basic version, the cost free version, only allows for one interactive information window per map. Since one goal of this project is to compare place-based images this limitation would provide an impediment to its use in this application.

Carto provides a platform that includes placebased location keys with information windows that are interactive. The free version allows for multiple information windows linked to specific locations. This provides the most effective tool for the goals of this project.

There are several possibilities facilitated by Carto. Carto provides a layer tool that allows a user to toggle between sets of information and sets of visual images. This is very useful in comparing the Jeanneret locations to the Ruskin locations in Florence. Further, is that Carto includes unlimited information windows that are easily adaptable. The widget function allows the user to open a text window to customise the information window function (Figure 3). Working with this creatively results in several advantageous outcomes including the association of multiple images to places that may be seen simultaneously. This is achieved by creating galleries in Pinterest made up of pertinent images. In this case the images are of Jeanneret/Le Corbusier's sketches and other images of the source material that he was sketching. The allows the researcher and historian to find a location on the map that Jeanneret/Le Corbusier sketched such as the St. Mark sculpture by Donatello for example, click on the location marker to open the information window, then click on the link in the window to see Jeanneret/Le Corbusier's sketches in the Pinterest gallery. These may be compared to other images by Donatello, or sketches of the St. Mark sculpture by other artists by linking to a second Pinterest gallery.

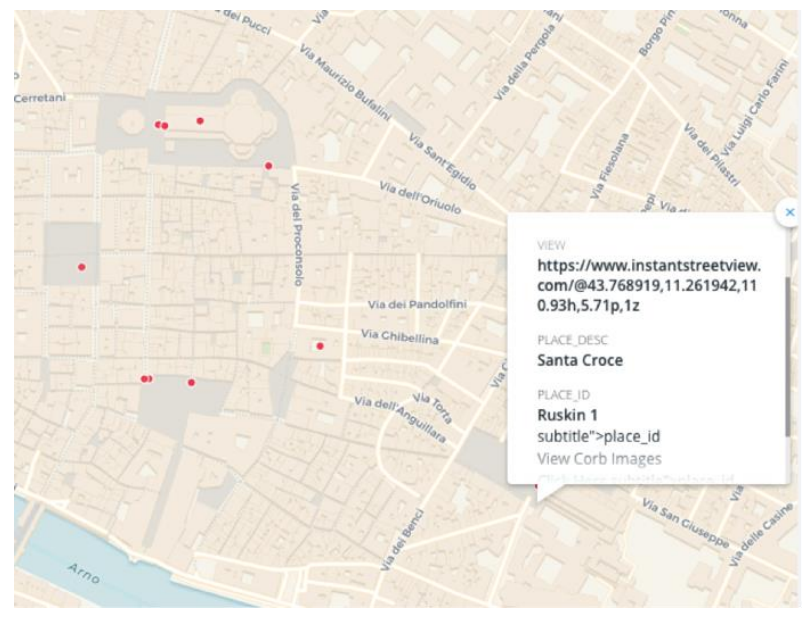

Figure 3: Site Locations in Carto.

The capacity of the information window may be expanded by providing a link to street views of locations indicated on the map. Instant Streetviews works well in providing images that provide current views of locations of interest. An advantage of Streetviews is that it also includes views of publicly accessible interior spaces unlike Google Earth, which only provides exterior views. Streetviews is crowd-sourced which means that the panoramic images are not of a consistent quality. A further disadvantage is that the people shown in the panoramic images are not always shown completely or are shown in several locations at one time as they are photographed as they move within the framework of the camera. An advantage to Streetviews is that the inclusion of people in the images provides a sense of scale to the artwork sculpture and architecture. Further, is that there is a sense of movement within each panoramic image which gives each view a sense of realism as the views represent populated spaces. 


\begin{tabular}{|c|c|c|c|c|c|}
\hline $\begin{array}{l}\text { cartodb_id } \uparrow \vdots \\
\text { number }\end{array}$ & $\begin{array}{l}\text { the_geom } \\
\text { geometry }\end{array}$ & $\begin{array}{l}\text { year } \\
\text { number }\end{array}$ & $\begin{array}{l}\text { _unnamed } \\
\text { string }\end{array}$ & $\begin{array}{l}\text { place_desc } \\
\text { string }\end{array}$ & $\begin{array}{l}\text { place_id } \\
\text { string }\end{array}$ \\
\hline 1 & $11.248263,43.775085$ & 1907 & http://upload.wikimedi... & Spanish Chapel & Corb 1 \\
\hline 2 & $11.249199,43.774069$ & 1907 & & Santa Maria Novella & Corb 2 \\
\hline 3 & $11.258271,43.770361$ & 1907 & & Bargello & Corb 3 \\
\hline 4 & $11.252426,43.771064$ & 1907 & & Orsan Michele St Matt... & Corb 4 \\
\hline 5 & $11.255336,43.769955$ & 1987 & & Signoria & Trach 1 \\
\hline 6 & $11.256065,43.769909$ & 1987 & & Signoria & Trach 2 \\
\hline 7 & $11.257389,43.772599$ & 1987 & & Duomo & Trach 3 \\
\hline 8 & $11.255501,43.773112$ & 1987 & & Duomo & Trach 4 \\
\hline 9 & $11.262016,43.768624$ & 1894 & & Santa Croce & Ruskin 1 \\
\hline 10 & $11.256215,43.773158$ & 1894 & & Duomo & Ruskin 2 \\
\hline 11 & $11.24949,43.774902$ & 1894 & & Spanish Chapel & Ruskin 3 \\
\hline 12 & $11.255608,43.773096$ & 1417 & & Duomo & BR 1 \\
\hline 13 & $11.255259,43.769953$ & 1417 & & Signoria & BR 2 \\
\hline
\end{tabular}

Figure 4: Data window in Carto.
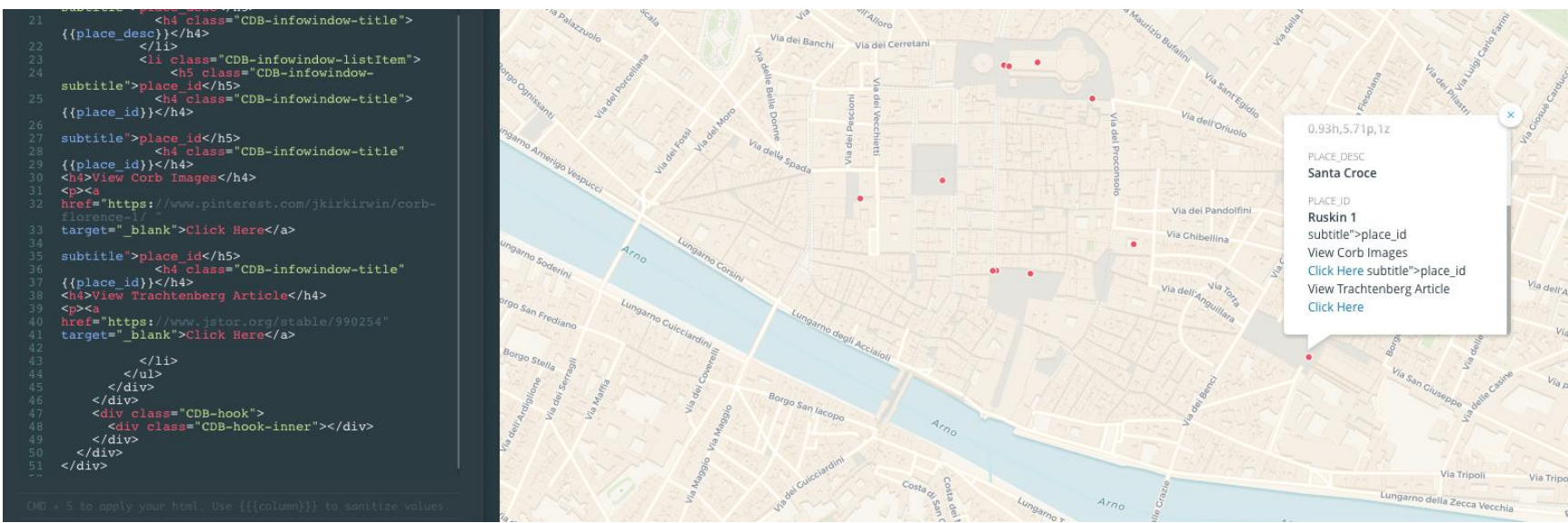

Figure 5: Carto information window and text window.

A third way to enhance the capacity of information windows in Carto is to link written material within the information window. This is possible using the text window and inserting code that links to the external resource (Figures 4 and 5). With this function it is possible to link journal articles or other digitised texts to a place marker. With this specific project it was important to recognise the relationship between the historical urban context and the art that was produced within it. One of the primary sources that addresses this relationship is Trachtenberg's article, "What Brunelleschi Saw: Monument and Site at the Palazzo Vecchio in Florence." This was expanded into a book titled,
Dominion of the Eye, which looked into other elements within the urban fabric of the historic centre of Florence and how this influenced the development of late medieval and early Renaissance art (Trachtenberg 1988 and 1997) Having these texts available alongside panoramic images of the piazzas and buildings in Florence and alongside image galleries including art architecture and drawings is useful while developing insights into connections and themes between and amongst source material.

The Trachtenberg journal article is accessible through JSTOR and has a permanent URL. When 
the URL is inserted into the line of code that places it within the information window. Clicking on the link takes the reader to the JSTOR article. But the article appears in thumbnail images. The reader has to then log into a JSTOR account to read the article. This is different from the links to the Pinterest image galleries because with Pinterest the link leads directly to the images. In this case there is an extra step required, logging in to JSTOR. This is a minor drawback but raises an important issue. Since the reader is required to log into JSTOR why not open a separate window outside the Carto platform then access the journal article from the separate window? The answer has to do with the nature of the research question. If the question is inherently place-based then having the research immediately accessible within a geo located format is sensible. For example, the research question behind this project is how Jeanneret/Le Corbusier's experience of medieval art and architecture was mediated by John Ruskin's itinerary in Mornings in Florence. Of further interest is how movement through the historic centre of Florence presents a dynamic spatial environment that has influenced the development of western art and architecture at critical points in history.

The mapping overlays helps to explore these questions showing the locations of Jeanneret's sketches compared to Ruskin's itinerary, the location of Brunelleschi's mirror panels, and the key locations essential to Trachtenberg's hypothesis. These link to "street views" to allow a comparison between what was sketched by Jeanneret/Le Corbusier and specific viewpoints as they currently exist.

\section{CONCLUSION}

Digital media provide several new opportunities to scholars in the visual arts. Much of the work in digital scholarship in architecture in particular focuses on digital reproduction of buildings that have been destroyed or partially destroyed for which there is enough documentary evidence to inform a hypothesis as to what the building may have been constructed and what it may have looked like. These are important efforts. What this project proposes is that there are ways to use digital media to inform advanced research through the interactive organization of source material and the visualization of material in novel ways.

How this compares to previous developments is worth noting. The presentation of orthographics with details and proportions in Andrea Palladio's format allowed for the distribution of Palladio's classicism only limited by the access to Palladio's text. His use of technology, the printed text, was a significant innovation that set the paradigm for printed architectural material for centuries.

Wolfflin's comparative method depended upon the ability to observe two images simultaneously and interchangeably. His early use of the projected image was an application of technology to pedagogy and historical inquiry that underlies much of the current methods of art and architectural history even if these go largely unrecognised.

Similar opportunities exist with digital media. Current media allow for the dynamic placement of images alongside materials that were intended for static media. Because the Streetview format is crowd sourced it provides an unlimited number of images of interior and exterior located to a specific place. Importantly, these represent individual perceptions that may or may not be academically informed. Who has control over the image and how does one engage the visual image and how does one engage spatial material are questions that take a central position within this dialogue. If anyone with a cell phone and internet access is now a photographer, is anyone with a cell phone and internet access who distributes images of art and architecture an historian?

The main points of this project may be summarised with the following elements:

- The plotting of the places on a map to develop new conceptual frameworks for art and architectural research.

- The collection of unlimited images associated with these places.

- The collection of images organised thematically such as the Jeanneret/Le Corbusier images and any that result from Ruskin.

- The correlation of street view and interior view.

- The association of place to text.

- The recognition of dynamic perception.

These points open new approaches that move well beyond the historian of art and architecture studying two or three images and a dozen or so related texts attributing to him or herself privileged access to these. 


\section{REFERENCES}

Brillhart, J. (2016) Voyage Le Corbusier: Drawing on the Road. W. W. Norton and Company, New York.

Brooks, H. A. (1997) Le Corbusier: The Formative Years. University of Chicago Press, Chicago.

Ruskin, J. (1891) Mornings in Florence: Being Simple Studies of Christian Art for English Travellers. New York.
Trachtenberg, M (1988) 'What Brunelleschi Saw: Monument and Site at the Palazzo Vecchio in Florence', Journal of the Society of Architectural Historians, 47, 14-44.

Trachtenberg, M. (1997) Dominion of the Eye: Urbanism, Art, and Power in Early Modern Florence. Cambridge University Press, Cambridge. 